\title{
Studies of the spread of radioactive gold colloid
}

\author{
C. B. D'A. FEARN \\ Royal Sussex County Hospital, Brighton
}

The use of ${ }^{198} \mathrm{Au}$ in the treatment of patients with classical or definite rheumatoid arthritis has been studied clinically and the spread of the isotope from the knee to the rest of the body has been investigated. 29 knees in 23 patients were injected, usually in a dose of 10 to $12 \mathrm{mCi}$., although the dosage ranged from 7 to $30 \mathrm{mCi}$. The particle size was 10 to $13 \mu$ (maximum 20 $\mu$ ). The patients were followed for 24 to 104 months and were examined for pain, stiffness, joint temperature and tenderness, effusion, and synovial hypertrophy.

A retrospective group of fifteen knees in thirteen patients previously treated by Dr. A. G. S. Hill at Stoke Mandeville Hospital forms part of the total. The remainder were personally selected, treated, and followed.

Table I shows the results; these are expressed in percentages, for sometimes there were insufficient data in the retrospective group to make an assessment. These results have been reported in full elsewhere (Fearn, 1972).

Table I Results with ${ }^{198} \mathrm{Au}$

\begin{tabular}{ll}
\hline Factor tested & $\begin{array}{l}\text { Improvement } \\
\text { (per cent.) }\end{array}$ \\
\cline { 1 - 2 } Pain & 90 \\
Stiffness & 85 \\
Tenderness & 70 \\
Effusion & 89 \\
Hypertrophy & 57 \\
Temperature & 80 \\
Movement & 86 \\
Power & 41 \\
\hline
\end{tabular}

The spread of the isotope from the knee was studied by scanning a patient with classical rheumatoid arthritis who had had previous bilateral synovectomies for severely damaged knees. He received $5 \mathrm{mCi} .{ }^{198} \mathrm{Au}$ into each knee on the same day, a total of $10 \mathrm{mCi}$. The spread of the radioactive material was recorded with a Nuclear Enterprises gamma camera. 1 hour after the injections the radio-isotope was contained in the synovial cavities of the knees. The illustrations show the uniform distribution of the gold in the antero-posterior (Fig. 1), postero-

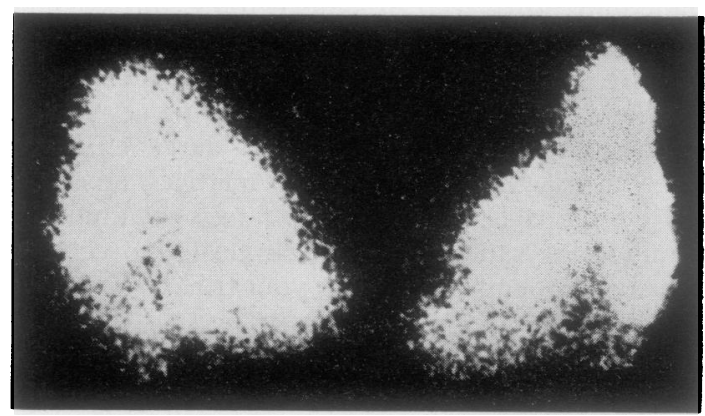

FIG. 1 Antero-posterior scan of both knees 1 hour after injection of radio-isotope, showing uniform distribution in synovial cavity. 20,000 counts per second

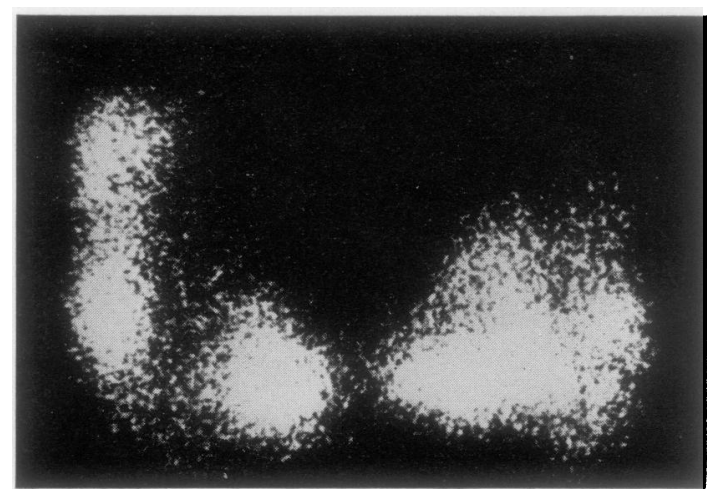

FIG. 2 Postero-anterior scan after 1 hour

anterior (Fig. 2), and lateral views (Fig. 3). By comparison, in surgical synovectomy, the synovium at the back of the joint is untouched. After 1 hour some of the isotope had reached the inguinal, external iliac, and para-aortic lymph nodes (Fig. 4). In the abdomen the count rate was 200 counts per second and at the knee 20,000, indicating a leakage of 1 per cent.

At 27 hours, the isotope was in the upper thorax and liver, as shown in Figs 5 and 6, as well as the knees and abdomen (Figs 7 and 8). The situation at 75 hours was similar, but activity was disappearing 


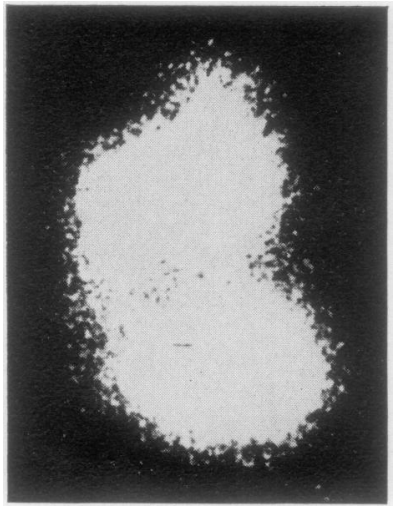

FIG. 3 Lateral scan of right knee after 1 hour

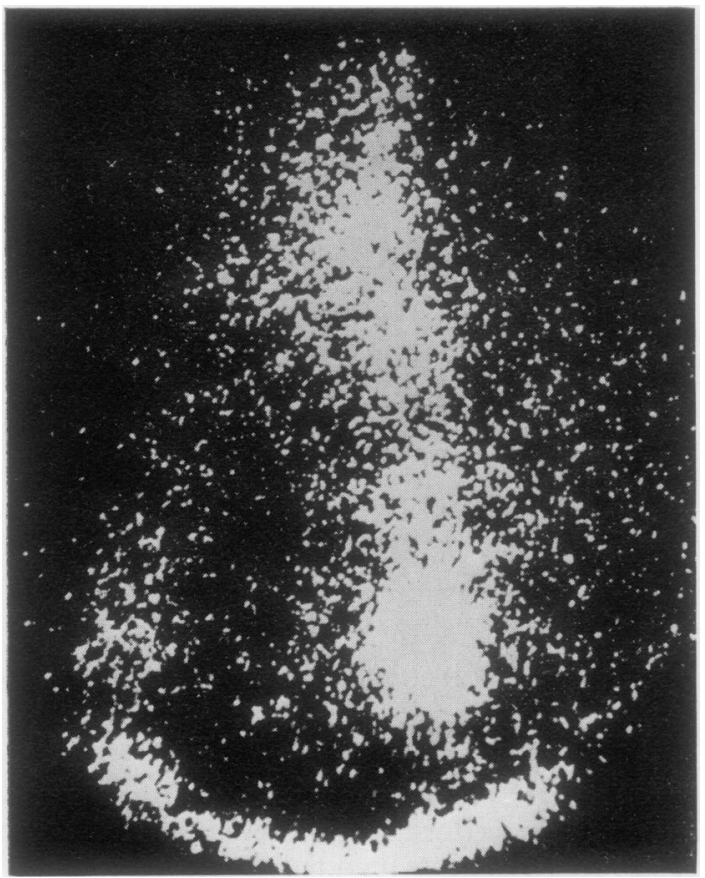

FIG. 4 Antero-posterior scan of abdomen after 1 hour, showing radio-isotope in inguinal and external iliac lymph nodes. 200 counts per second

from the liver (Fig. 9), and this is also shown at 145 hours (Fig. 10). No activity was detected in the spleen of this patient but activity in the liver and spleen has been recorded on a more sensitive scintigram in another patient. A graph (Fig. 11, overleaf) of the count-rates (semi-logarithmic) shows that there is an initial delay in leakage from the joint before the values in the abdomen and liver increase. This graph shows a further reduction in the dosage of radiation in the tissues outside the knees.

This patient had severely damaged knees and

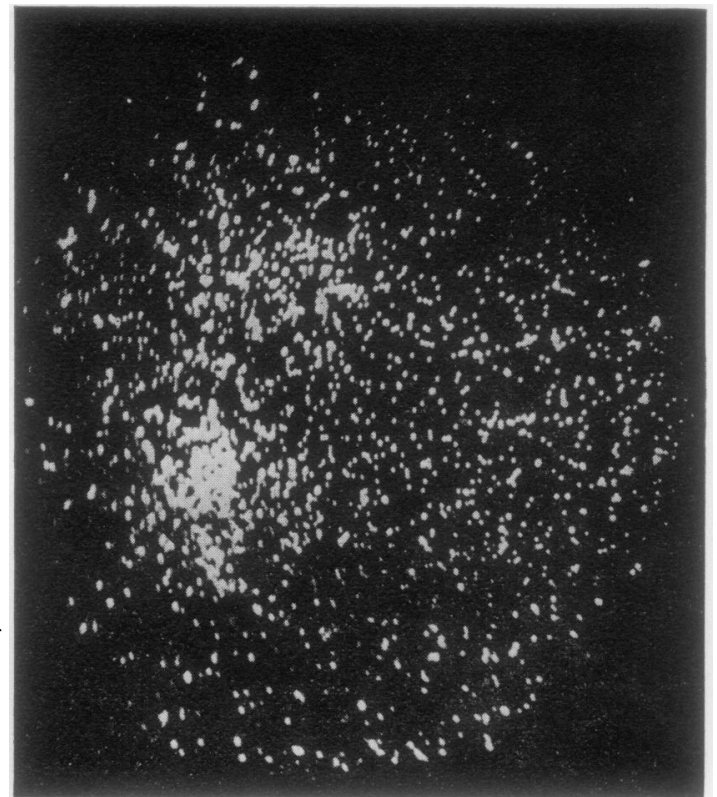

FIG. 5 Antero-posterior scan of thorax after $27 \mathrm{hrs.}$ 50 counts per second. Isotope present in thoracic duct

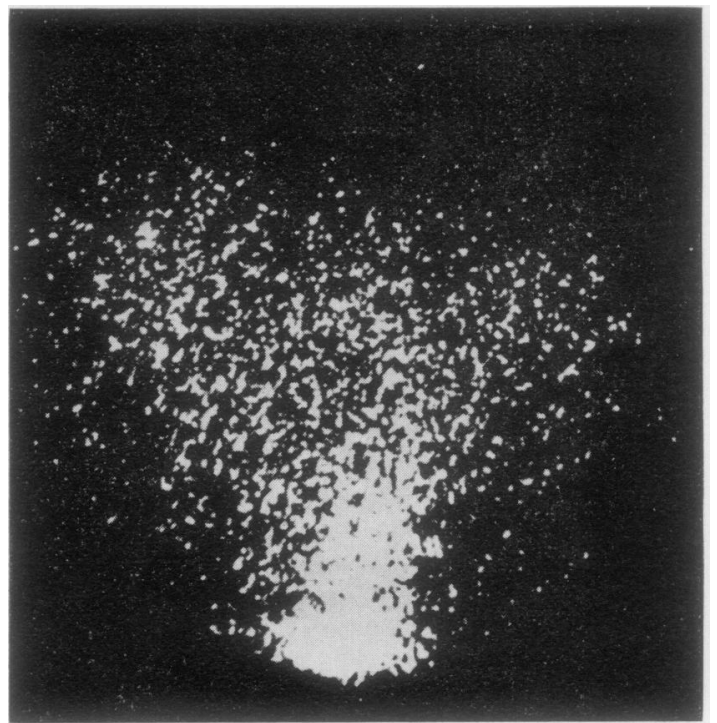

FIG. 6 Antero-posterior scan of liver after 27 hrs. 550 counts per second. There is a little in the liver and more in the para-aortic nodes

about 1 per cent. of the radioactivity leaked away from them. Chromosome damage in circulating lymphocytes (Table II) is shown to be higher in 'late' cases with joint damage than in 'early' cases, with respect to the dosage injected, damaged chromosomes occurring in larger numbers where there is severe 


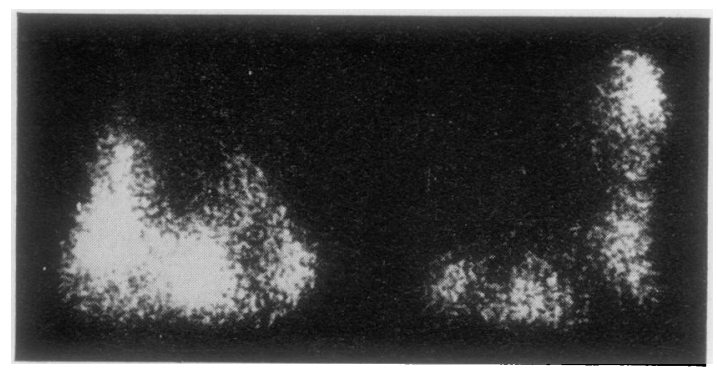

FIG. 7 Antero-posterior scan of knees after $27 \mathrm{hrs}$. 12,000 counts per second

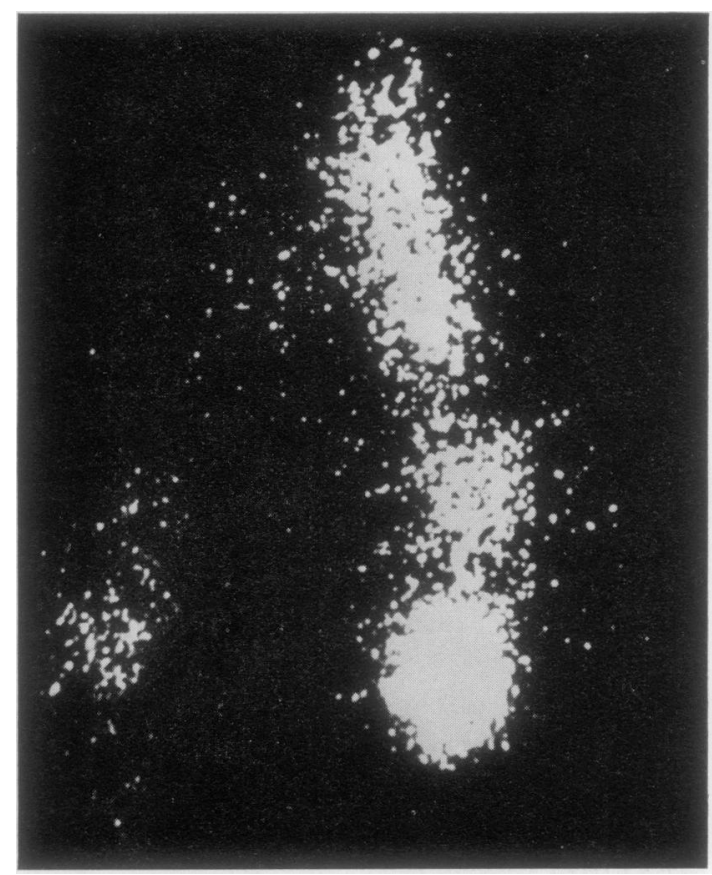

FIG. 8 Antero-posterior scan of abdomen and pelvis after 27 hrs. 1,200 counts per second

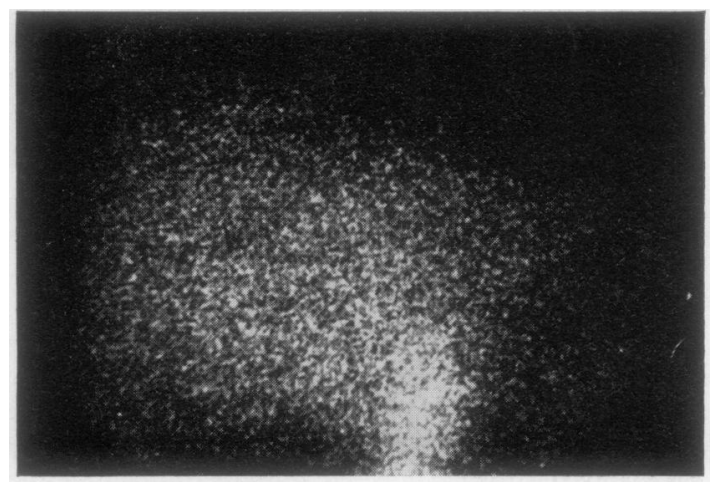

FIG. 9 Antero-posterior scan of liver and para-aortic lymph nodes after 75 hrs. 400 counts per second

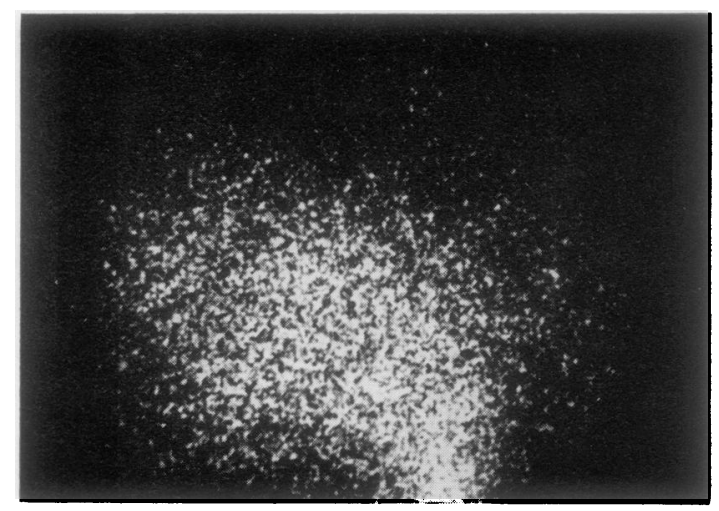

FIG. 10 Antero-posterior scan of liver and para-aortic lymph nodes after 145 hrs. 220 counts per second

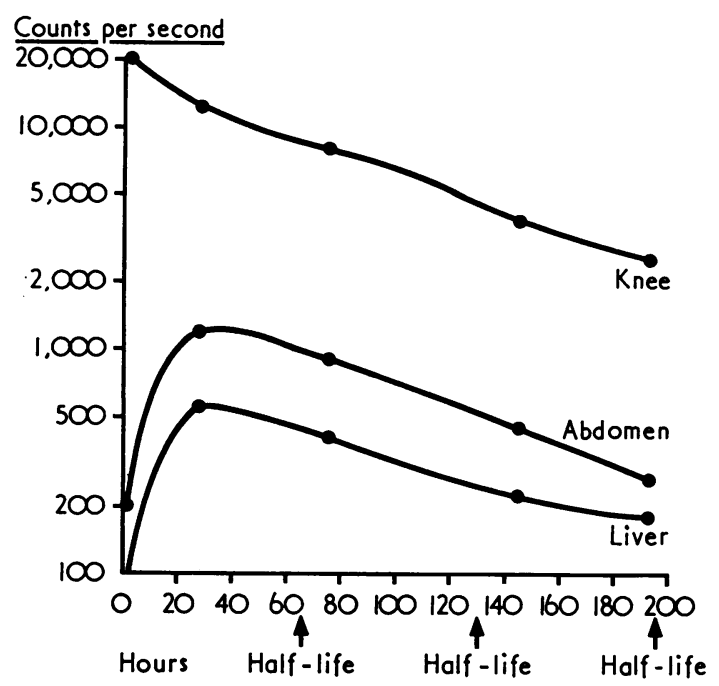

FIG. 11 Graph of count rates

joint damage. These figures are taken from chromosome counts performed by Stevenson and others (1973) on the patients reported above.

I wish to thank Dr. A. G. S. Hill and Dr. A. G. Mowat for permission to study and treat patients under their care and Dr. Fred Wright and Mr. Dan Macey, M.Sc., for the scans.

\section{Discussion}

DR. EDMUNDS Is any of this radioactivity eventually excreted through the kidneys; is there any in the urine at this stage?

MR. FEAR N We have never detected any, but we have not looked for it specifically or carefully. We have not found it in the kidneys, and most of it appears from the histological assessment to be held in the reticuloendothelial system. I suppose that it decayed before it was detected. 
Table II Chromosome damage related to joint damage and dosage of radio-isotope

\begin{tabular}{|c|c|c|}
\hline $\begin{array}{l}\text { No. of damaged lymphocytes } \\
\text { per } 100 \text { cells counted }\end{array}$ & $\begin{array}{l}\text { Duration of } \\
\text { disease } \\
\text { (radiological } \\
\text { evidence) }\end{array}$ & $\begin{array}{l}{ }_{(m C i .)}^{198} \mathrm{Au} \text { dosage } \\
\left(m,{ }^{2}\right.\end{array}$ \\
\hline 0 & $\begin{array}{l}\text { Early } \\
\text { Late }\end{array}$ & 1012 \\
\hline 1 & $\begin{array}{l}\text { Early } \\
\text { Late }\end{array}$ & $\begin{array}{lll}28 & 12 & 10 \\
23 & 12\end{array}$ \\
\hline 2 & $\begin{array}{l}\text { Early } \\
\text { Late }\end{array}$ & 22 \\
\hline 3 & $\begin{array}{l}\text { Early } \\
\text { Late }\end{array}$ & $\overline{27}$ \\
\hline 4 & $\begin{array}{l}\text { Early } \\
\text { Late }\end{array}$ & $\overline{10} 1010+12 *$ \\
\hline 5 & $\begin{array}{l}\text { Early } \\
\text { Late }\end{array}$ & $2712 \ddagger$ \\
\hline 6 & $\begin{array}{l}\text { Early } \\
\text { Late }\end{array}$ & $12 \ddagger 15$ \\
\hline 8 & $\begin{array}{l}\text { Early } \\
\text { Late }\end{array}$ & 30 \\
\hline 10 & $\begin{array}{l}\text { Early } \\
\text { Late }\end{array}$ & $\underline{46}$ \\
\hline
\end{tabular}

Patient showed a systemic reaction

t Patient received phenylbutazone

¥ Patient had severe joint damage

DR. RAMSEY We also did a series of gold cases, and we measured the urine content. It was extremely low, always less than 1 per cent., more of the order of $0 \cdot 1$ per cent.

PROFESSOR INGRAND Just one comment; we feel now that passive movements of the knees after injection are not only unnecessary but dangerous, because you can passively force the colloid to bypass the synovial membranes. We abandoned passive movement 2 years ago, and we now put the joint in splints after the injection.
MR. FEARN Yes, I am sure this is right, and it would be my intention to repeat these studies in patients who have been rested. The worry here is that there must be precipitation of the radiocolloid onto cartilage if the knee is mobilized. Cartilage is cleared by mechanical action, and I wonder if there will not be an increase in radionecrosis of cartilage. DR. GUMPEL But scans and the evidence from animals show that, in fact, the radiocolloid does not stay on the cartilage.

DR. ANSELl Has anyone done any studies with radiogold completely immobilizing the patient for 48 hours afterwards to see if this spread is reduced? DR. GUMPEL In arthrography, we use intravenous pyelography contrast medium, such as Conray, which is rapidly cleared from the inflamed knee. The current practice is to get the patient to do one or two ' $k$ nees bends', perhaps four or five, to distribute the Conray very quickly around the knee. Often on the subsequent film, you can see several little fine channels going up into the upper thigh and also in the front of the knee and surely this is radio-opaque material which has been pushed out of the knee, perhaps by these 'knees bends' into the lymphatics; I certainly support anybody who thinks the knees should be rested straight away and that we should not try to re-distribute the material in the knee by moving the joint.

MR. FEARN I do not entirely agree with this therapeutic point of view, because, on Professor Ingrand's scintigram, he showed that radioactivity was located pictorially in certain parts of the knee. I wonder if this is because the knee had been rested and not put through a full range of movement. My contention at that time was purely theoretical, in that the best way to distribute the radioactivity was to put the knee through a full range of movement. 